\title{
COVID-19-Associated Carotid Atherothrombosis and Stroke
}

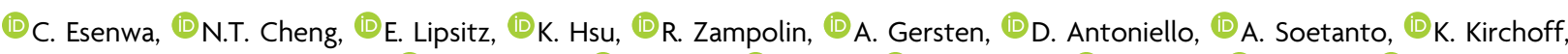 \\ (1) A. Liberman, (1)P. Mabie, (1)T. Nisar, (1)D. Rahimian, (1)A. Brook, (1)S.-K. Lee, N. H. Haranhalli, \\ (1DD. Altschul, and $\mathbb{1}^{\mathrm{D}} \mathrm{D}$. Labovitz
}

O- 르

\section{ABSTRACT}

SUMMARY: We present a radiology-pathology case series of 3 patients with coronavirus disease 2019 (COVID-19) with acute ischemic stroke due to fulminant carotid thrombosis overlying mild atherosclerotic plaque and propose a novel stroke mechanism: COVID-associated carotid atherothrombosis.

ABBREVIATIONS: ACE2 = angiotensin-converting enzyme 2; CCA = common carotid artery; COVID-19 = coronavirus disease 2019; RT-PCR = reverse-transcriptase polymerase chain reaction; SARS-CoV-2 = Severe Acute Respiratory Syndrome coronavirus 2

C arotid plaque size is a predictor of ischemic stroke and guides treatment strategies. ${ }^{1}$ However, since 1952, when C. Miller Fisher associated carotid atherosclerosis with stroke, there remained an unresolved question: Why did the plaque become symptomatic when it did? ${ }^{2}$ Inflammation has been proposed as the main mediator ${ }^{3}$ of carotid disease, and with the emergence of the coronavirus disease 2019 (COVID-19), we may have entered a new era of large-vessel atherothrombotic disease with a unique opportunity to address Fisher's question.

COVID-19 causes acute cardiovascular events with unusual manifestations. ${ }^{4}$ Reports of patients with intracranial large-vessel occlusion implicates cerebrocervical vessel involvement as part of the spectrum of cardiovascular events in COVID-19., ${ }^{5,6}$ One mechanism under investigation is related to the binding of Severe Acute Respiratory Syndrome coronavirus 2 (SARS-CoV-2) on the human angiotensin-converting enzyme 2 (ACE2) receptor. ${ }^{7}$ ACE2 is highly expressed in the endothelium and has been directly implicated in mediating vessel wall inflammation, oxidative stress, and atherosclerosis. ${ }^{8}$ Evidence of viral infection with endothelial inflammation and apoptosis in bowel and lung tissue of patients with COVID-19 has been termed "endotheliitis."

Received May 30, 2020; accepted after revision June 26.

From the Departments of Neurology (C.E., N.T.C., D. Antoniello, A.S., K.K., A.L., P.M., T.N., D.R., D.L.), Radiology (K.H., R.Z., A.B., S.-K.L.), Pathology (A.G.), Neurosurgery (N.H., D. Altschul), and Cardiothoracic and Vascular Surgery (E.L.), Montefiore Medical Center/Albert Einstein College of Medicine, Bronx, New York.

Drs Esenwa and Cheng contributed equally as primary authors.

Please address correspondence to Charles Esenwa, MD, MS, Montefiore Medical Center, 3316 Rochambeau Ave, 4th floor, Bronx, NY 10467; e-mail: cesenwa@montefiore.org

- Indicates open access to non-subscribers at www.ajnr.org

Indicates article with supplemental on-line table.

http://dx.doi.org/10.3174/ajnr.A6752
We describe 3 patients with COVID-19 with acute ischemic stroke due to fulminant carotid thrombosis overlying mild atherosclerotic plaque. We review the clinical course, advanced imaging, and pathologic examination and propose a previously undescribed COVID-19-related stroke mechanism.

\section{Case Series Description}

From April 9 to 23, 2020, a 2-week period when COVID-19 peaked in New York City, we encountered 3 patients with COVID-19 and partially occlusive cervical carotid thrombosis. Patients 1 and 3 presented to our tertiary-care hospital and comprehensive stroke center (Montefiore Medical Center - Moses Campus) with acute stroke, while patient 2 developed stroke as an inpatient. The patients shared comorbid conditions, biomarker profiles, and radiographic features (On-line Table). CT angiography showed nonocclusive thrombus adherent to the distal common carotid artery (CCA) and carotid bifurcation on CTA of the head and neck (Fig 1), with cortical acute ischemic strokes ipsilateral to the carotid lesion in all patients. Patient 1 also had an incidental arotic arch thrombus adherent to the vessel wall. All 3 patients demonstrated peripheral ground-glass pulmonary findings consistent with COVID-19 infection. Patients 1 and 3 were diagnosed with COVID-19 on the basis of the clinical course, pulmonary findings, and a positive reverse-transcriptase polymerase chain reaction test (RT-PCR) for SARS-CoV-2. Patient 2 presented with signs and symptoms of COVID-19 pneumonia, had profound pulmonary findings consistent with COVID-19 pneumonia on imaging, and while RT-PCR results were negative, the patient tested positive for the SARS-CoV-2 antibody. The patients were treated with apixaban or intravenous unfractionated heparin without resolution of the thrombus. Two were also on antiplatelet therapy before undergoing 


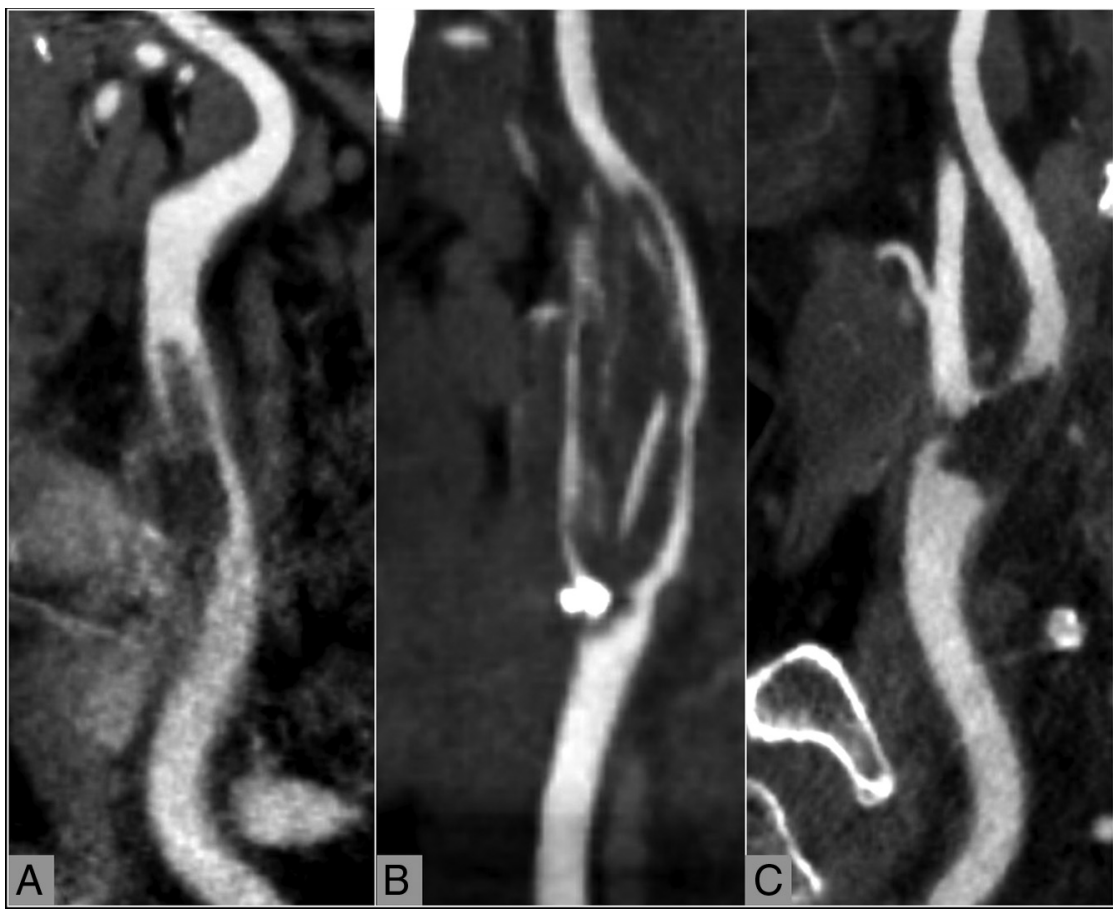

FIG 1. CT angiogram of cervical vessels showing thrombosis. Curved planar reformatted CTA neck images demonstrate adherent thrombus in the left mid-common carotid artery (patient 1) (A). The thrombus appears to start from the right carotid bifurcation and extend toward both the internal and external carotid arteries (patient 2) $(B)$, and the left carotid bifurcation shows wedge-shaped intraluminal thrombus (patient 3) (C). Note the relatively minor mineralized and nonmineralized atherosclerotic plaque adjacent to the thrombus in each patient. an approximate $6 \times 6 \mathrm{~mm}$ area of ulceration in the carotid bulb at the area of adhesion. Considerable inflammation was noted in the area of the bulb. The specimen showed mild-to-moderate atherosclerotic disease with intimal thickening, plaque, and mural calcification. There were scattered mononuclear cells in an area of thickened intima.

\section{DISCUSSION}

We propose a novel stroke mechanism, COVID-19-associated carotid atherothrombosis, and review the imaging and pathologic findings. While still not fully understood, it is believed that an overwhelming innate immune response to SARS-CoV-2 results in 1) systemic inflammation, 2) associated coagulopathy, and 3) local endotheliitis, in some. ${ }^{9,10}$ In the patients described herein, SARSCoV-2 endotheliitis may have destabilized mild chronic atherosclerotic plaque to initiate thrombosis, with subsequent propagation due to a prothrombotic state broadly termed "COVID-19-associated coagulopathy."11 Reports of SARSCoV-2-mediated endotheliitis support this possible mechanism because local open thrombectomy and carotid endarterectomy. Surgical intervention was chosen to facilitate complete clot removal and perform endarterectomy as needed, as well as to minimize embolic risk from the intraluminal thrombus.

Open exploration in patient 1 revealed an organized thrombus moderately adherent to the wall of the CCA over a length of approximately $1 \mathrm{~cm}$ and encompassing approximately $70 \%$ of its circumference. A free-floating tail of thrombus extended distally to the level of the carotid bifurcation. Moderate plaque with marked inflammatory changes at the area of clot adherence did not cause considerable plaque-related luminal stenosis. Microscopic examination confirmed thrombus adherent to the wall. The intima had inflammatory infiltrates as well as some degenerative cellular debris consistent with apoptosis (Fig 2C).

Open exploration in patient 2 identified a small, moderately adherent organized thrombus in the carotid bulb with a smaller contiguous portion adjacent to an area of calcified plaque extending into the external carotid artery. Gross examination found only mild inflammatory changes at the level of clot adherence. Microscopically, the intima was thickened with evolving calcification consistent with atherosclerotic disease. A portion of the intima contained mononuclear inflammatory cells (Fig 2A, $-B$ ).

Patient 3 had organized, nearly occlusive thrombus, extending into the proximal internal carotid artery, with moderate plaque and inflammation might alter endothelial functions. ${ }^{12,13}$ Pathologic reports of multiorgan thrombotic microangiopathy in patients with COVID-19 support our theory that COVID-19-associated coagulopathy may have additionally and perhaps synergistically contributed to the disproportionately high intraluminal thrombus burden relative to the mild underlying atherosclerotic plaque. ${ }^{14,15}$ On the basis of our limited case observation and the available literature, we further suggest the possibility that thromboinflammation related to COVID-19 may preferentially affect areas of atheromatous disease. Thus, our clinical impression in each of the described cases was that medical therapy with anticoagulation or antiplatelets alone was not sufficient to minimize the embolic risk; therefore, we recommended surgical intervention to facilitate complete clot and atheroma removal.

From this radiology-pathology case series, we deduce that areas of mild carotid atherosclerosis may be particularly prone to thrombus formation in patients with COVID-19 because of the unique combination of endotheliitis and COVID-19-associated coagulopathy. In the face of this pandemic, we may have coincidentally come closer to answering Fisher's question and are poised to address the next: How do we prevent COVID-19-associated carotid atherothrombosis?

Disclosures: Ava Liberman-RELATED: Grant: National Institutes of Health, Comments: The Mentored Patient-Oriented Research Career Development Award (K23).* Seon-Kyu Lee-UNRELATED: Consultancy: GraftWorks; Grants/ 

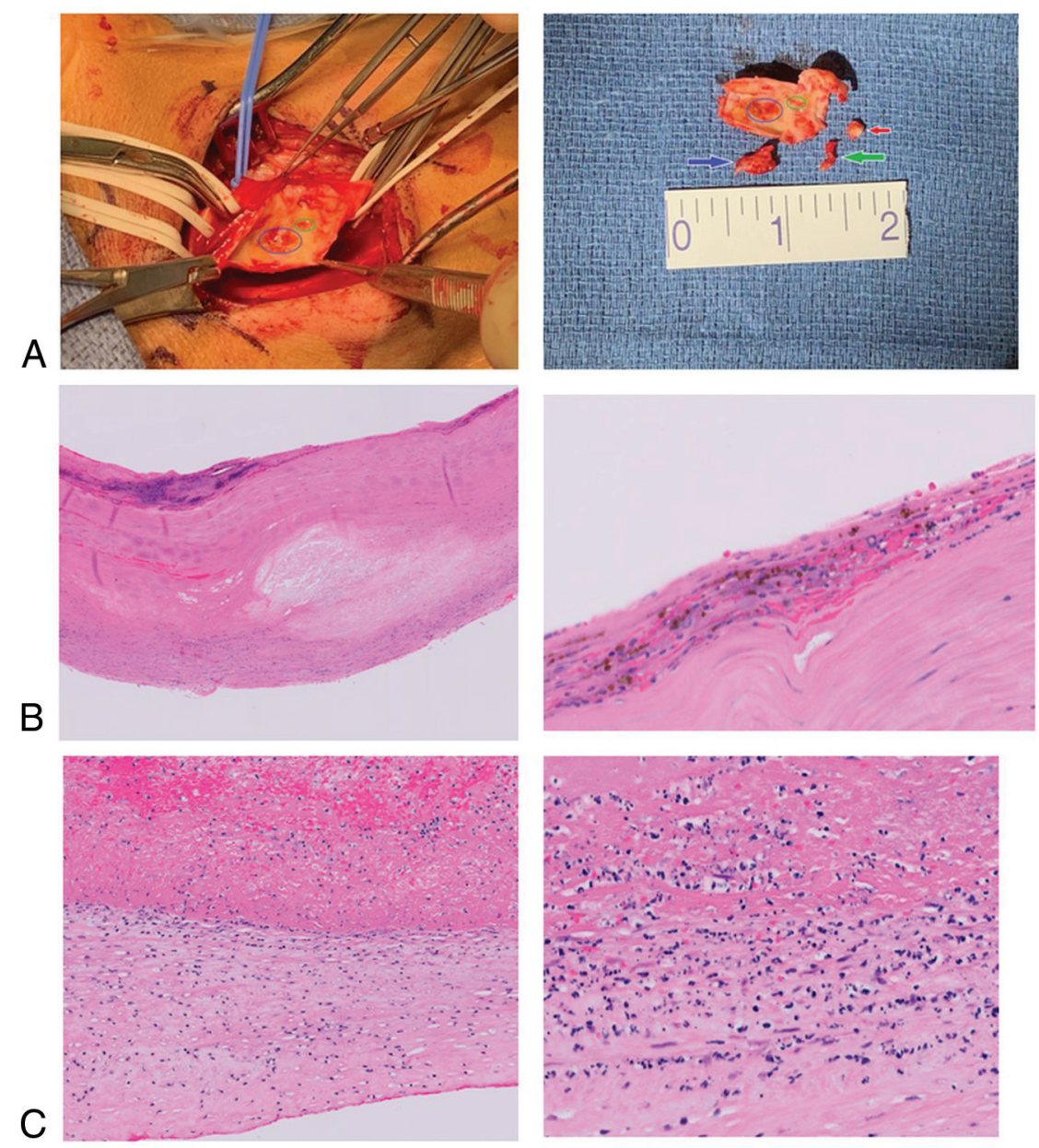

FIG 2. Gross and microscopic pathology. A, Surgical view in patient 2. The blue circle indicates the area to which the thrombus was adherent, and the green circle indicates the area to which the contiguous portion of the thrombus was adherent. Arrows represent the larger portion of thrombus (blue), smaller portion of thrombus (green), and calcified plaque at the external carotid origin (red). B, Microscopic examination of a specimen from patient 2. Hematoxylin-eosin stain shows intimal thickening, plaque formation, and calcification. Higher magnification shows an area of intima with mononuclear inflammatory cells and evolving plaque formation. C, Microscopic examination of a specimen from patient 1. Low-power hematoxylin-eosin stain shows the thrombus adherent to the wall (upper portion is thrombus; lower portion is the wall). Higher-power view of an area of adherent thrombus shows the intima with inflammatory infiltrate as well as some degenerating cellular debris that may indicate apoptosis.

3. Esenwa CC, Elkind MS. Inflammatory risk factors, biomarkers and associated therapy in ischaemic stroke. Nat Rev Neurol 2016;12:594-604 CrossRef Medline

4. Clerkin KJ, Fried JA, Raikhelkar J, et al. Coronavirus disease 2019 (Covid-19) and cardiovascular disease. Circulation 2020;141:1648-55 CrossRef

5. Oxley TJ, Mocco J, Majidi S, et al. Large-vessel stroke as a presenting feature of Covid-19 in the young. $N$ Engl J Med 2020;382:e60 CrossRef Medline

6. Wang A, Mandigo GK, Yim PD, et al. Stroke and mechanical thrombectomy in patients with COVID-19: technical observations and patient characteristics. J Neurointerv Surg 2020;12:648-53 CrossRef Medline

7. Hoffmann M, Kleine-Weber H, Schroeder S, et al. SARS-CoV-2 cell entry depends on ACE2 and TMPRSS2 and is blocked by a clinically proven protease inhibitor. Cell 2020;181:271-80.e278 CrossRef Medline

8. Tikellis C, Thomas MC. Angiotensinconverting enzyme 2 (ACE2) is a key modulator of the renin angiotensin system in health and disease. Int J Pept 2012;2012:256294 CrossRef Medline

9. Varga Z, Flammer AJ, Steiger P, et al. Endothelial cell infection and endotheliitis in Covid-19. Lancet 2020;395:141718 CrossRef Medline

10. Buja LM, Wolf DA, Zhao B, et al. The emerging spectrum of cardiopulmonary pathology of the coronavirus disease 2019 (COVID-19): report of 3 autopsies from Houston, Texas, and review of autopsy findings from other United States cities. Cardiovasc Pathol 2020;48:107233 CrossRef Medline

11. Connors J, Levy J. Covid-19 and its implications for thrombosis and anticoagulation. Blood 2020;135:2033-40 CrossRef Medline

12. Magro C, Mulvey JJ, Berlin D, et al. Complement associated microvascular injury and thrombosis in the pathogenesis of severe COVID-19

Grants Pending: National Institutes of Health grants, Comments: 1 R21 CA205892-01, 1 R21 EB022291-01. David Altschul-UNRELATED: Consultancy: MicroVention. *Money paid to the institution.

\section{REFERENCES}

1. Barnett HJ, Taylor DW, Haynes RB, et al; North American Symptomatic Carotid Endarterectomy Trial Collaborators. Beneficial effect of carotid endarterectomy in symptomatic patients with high-grade carotid stenosis. N Engl J Med 1991;325:445-53 CrossRef Medline

2. Fisher CM. Transient monocular blindness associated with hemiplegia. AMA Arch Ophthalmol 1952;47:167-203 CrossRef Medline infection: a report of five cases. Transl Res 2020;220:1-13 CrossRef Medline

13. Carsana L, Sonzogni A, Nasr A, et al. Pulmonary post-mortem findings in a series of COVID-19 cases from northern Italy: a twocentre descriptive study. Lancet Infect Dis 2020 June 8. [Epub ahead of print] CrossRef Medline

14. Connors JM, Levy JH. Thromboinflammation and the hypercoagulability of COVID-19. J Thromb Haemost 2020;18:1559-61 CrossRef Medline

15. Jackson SP, Darbousset R, Schoenwaelder SM. Thromboinflammation: challenges of therapeutically targeting coagulation and other host defense mechanisms. Blood 2019;133:906-18 CrossRef Medline 